International Journal of Engineering \& Technology, $7(4.35)(2018) 1-4$
International Journal of Engineering \& Technology
SPC
Website: www.sciencepubco.com/index.php/IJET
Research paper

\title{
Simulated Analysis and Review of Ocean Wave Power Generators
}

\author{
Sami Salama Hussen Hajjaj ${ }^{1 *}$, Ahmad Faizuddin Bin Ahmad Nazri ${ }^{2}$ \\ University Tenaga Nasional \\ ${ }^{1}$ Department of Mechanical Engineering, College of Engineering \\ ${ }^{2}$ Centre for Advanced Mechatronics and Robotics (CAMaRo) \\ Kajang, Selangor 43000, Malaysia. \\ *Corresponding authorE-mail: ssalama@uniten.edu.my
}

\begin{abstract}
With the exponential rise in human population, the need for energy is becoming a real challenge to many countries around the world. Shortages in fossil sources of energy and its rising prices are beginning to cause many socio-economic problems and unrest in many parts of the world. This brings the need and importance of finding alternative and reliable sources of power. In recent years, the power of ocean waves began to attract attention. In this article, a design of the Wave Power Generator device is presented. This design is introduced to improve the efficiency. The proposed design is compared with an existing device that exploits the sea waves, converting the its energy to electrical power. This study aims to show that the instrument would achieve a higher efficiency by generating a greater total of electricity with the appropriate design and focus. The study is simulated using MATLAB. Results of the study show the electricity energy generated improved up to $80 \%$ in contrast to the present instrument. The results of this work could lead the way towards more active implementations of wave power generators and the use of sustainable energy resources.
\end{abstract}

Keywords: Sustainability; Renewable energy resources; Wave generators, Wave power generators, Ocean power generators, Simulation analys is

\section{Introduction}

As electricity is becoming increasingly essential, more nations along with Malaysia will face a crisis in terms of producing electricity. In Malaysia, electrical energy is generated by burning fossil fuels.

Studies repeatedly show that the life of fossil fuels will come to an end in the near future. When that happens, the human population will encounter a dire energy problem, which could lead to major socio-economic problems. In recent years, there has been an increased interest in harvesting power from the ocean and seas that surround us, specifically in the Wave Power Generators (WPGs). These instruments are designed to convert the mechanical power from the waves to usable electrical power.

With an appropriate design and effective placement, the WPGs have a great chance to become a valid alternative source for sustainable energy and reduce the dependency on fossil fuel. Recent efforts have demonstrated successful implementations of WPGs [1-4]; however, these efforts also demonstrate WPGs' relatively low efficiency that is usually coupled with high infrastructural and maintenance costs. As such, this work attempts to investigate and determine the key design elements of the wave power generators and recommend optimum setup settings [1-4].

\section{The Working Principle of Wave Generators}

WPGs can be categorized by location or by the type of Power Take-Off (PTO) system implemented, or the actual method of converting mechanical ocean power to electricity. Locations include shorelines, nearshores, and offshores, while generator PTO types include Mechanical and Hydraulic [5-6].

As shown in Figure 1, a Hydraulic PTO would include hydraulic pistons, accumulators, hydroelectric turbines, air turbines and linear generators, all working in unison to capture wave energy and convert it to electrical energy [7].

Malaysia has strong sea wave energy at the east coast and its power is influenced by the wind strength. The coastal zones of Eastern Malaysian offer powerful wind that causes stronger and larger sea waves [8].

This study is concerned with generating electrical energy using sea waves; however, it has an additional goal that is to prove methods to improve the capacity of energy produced by an ocean wave generator. The overall target is to develop and produce these generators here in Malaysia all in an effort to become self-reliant when it comes to energy needs [8-10].

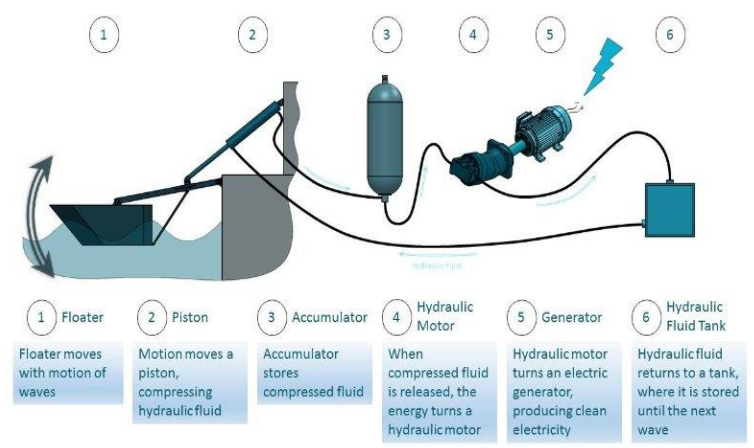

Fig 1: A hydraulic power take-off (PTO) system, [2] 


\subsection{Power Take-off (PTO) Methods}

PTO methods are an essential component of an ocean wave generator. PTO method determines the instrument's efficiency as well as the power output. Although all instruments have a distinct technique of acquiring the energy, the universal technique, that is via the traditional high-speed rotary electrical generators and other rotary components [8], remains the same. A major problem faced by researchers in the development of the instrument is how to drive these electrical generators. Hence, an alternate PTO mechanism is developed, which acts as a transmission system between the instrument interface and the electrical generator [5].

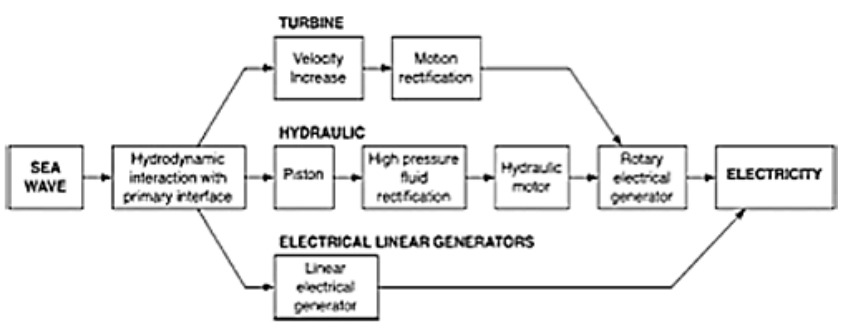

Fig. 2: Alternative approaches for a power take-off mechanism [3]

Most of the ocean wave generators use floaters as the fundamental component to capture energy. These floaters are attached to hydraulic pistons; so, when they rise and fall with the waves, the attached pistons move along in their hydraulic chambers which, in turn, compress the hydraulic fluids stored in the accumulator. Once enough pressure is built, the fluid is then released to actuate a series of hydraulic motors which move an electric generator, creating electricity $[9,10]$. From this point on, a conventional electrical power generation takes over; the current produced passes through either a conventional field wound or a multipolar wound. It could be further converted to AC or DC current depending on the requirements of the recipient entity [9].

\subsection{Types of Wave Power Generators}

Over the years, researchers experimented with different techniques for harvesting wave energy. The following approaches are the three most discussed approaches.

\subsubsection{Attenuator Design (or Ride-the-Wave Method)}

Attenuator designs focus on capturing wave power by placing the instrument corresponding to the sea surface, which is also known as "ride-the-waves". For instance, Pelamis is an attenuator instrument created by Ocean Power Delivery Ltd, now recognised as Pelamis Wave Power as seen in Figure 3 [11].

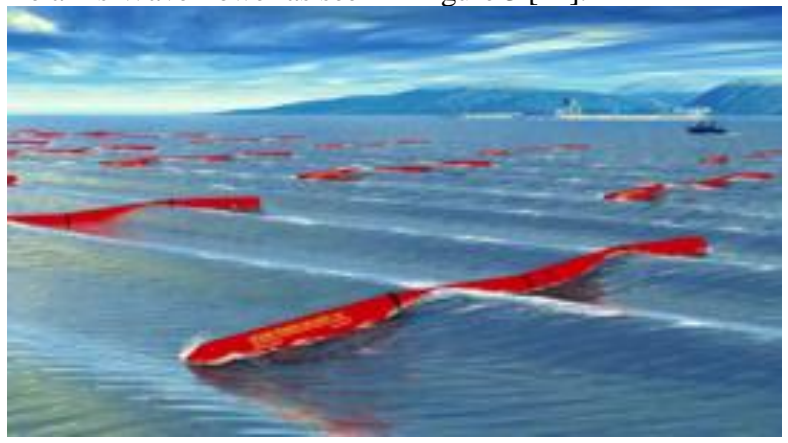

Fig 3: Attenuator-type wave power generator [5]

\subsubsection{Point Absorber}

One advantage of this device type is, it depends less on the wave course because of its small size. Point absorber could be positioned on the surface of the seas that hurls all over or fully immersed beneath the sea surface contingent upon the pressure difference. Point absorber has small proportions in relation to the incident wavelength as seen in Figure $4[5,6,12]$.

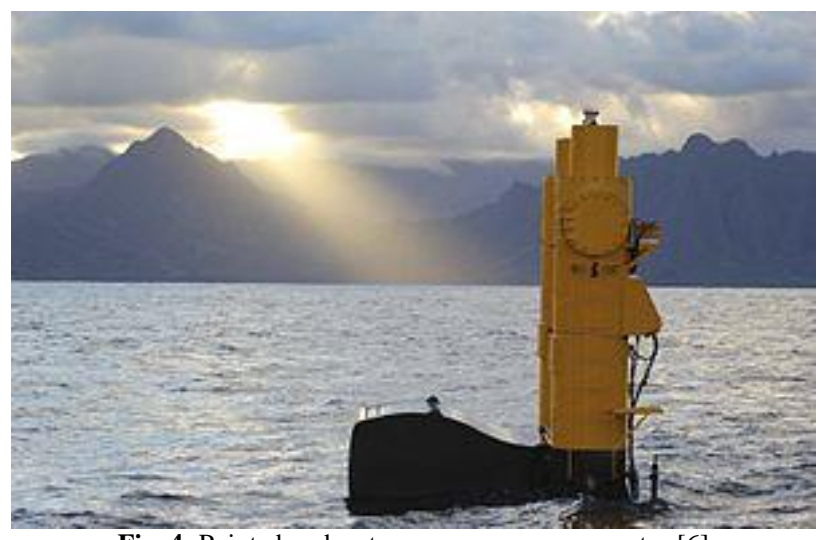

Fig. 4: Point absorber-type wave power generator [6]

\subsubsection{Terminator}

Terminator is an instrument placed vertically to the wave course, interrupting the waves. An instance of this instrument is Salter's Duck, created at the University of Edinburgh as seen in Figure 5 [7].

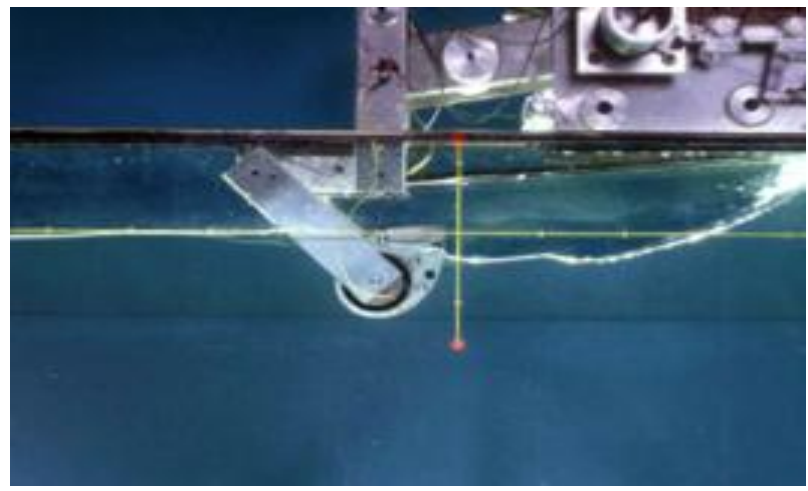

Fig 5: Terminator-type wave power generator [7]

\section{Simulated Analysis of Wave Generators}

Simulation analysis is broken down into three major steps: $3 \mathrm{D}$ modelling of major components, Matlab \& Simulink simulation, and performance optimization.
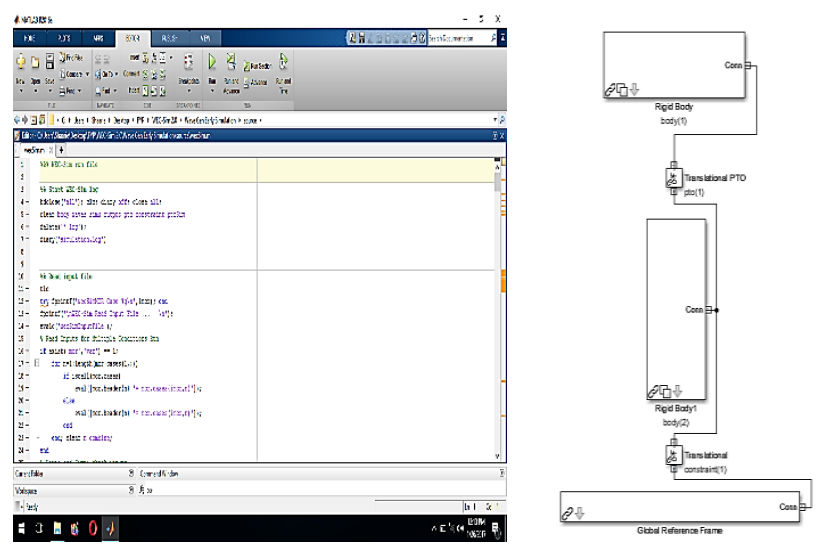

Fig 6: Screenshots of simulation models using MATLAB

\subsection{Performing 3D Modelling of the WPG Components}

The first step was to use SolidWorks to develop the 3D models of the various WPG components, which include the damping plate or 
base plate, floater, spar and ballast tank, power take-off unit, floaters, hydraulic motors, generators, etc, and their connections, as seen in Figure 6.

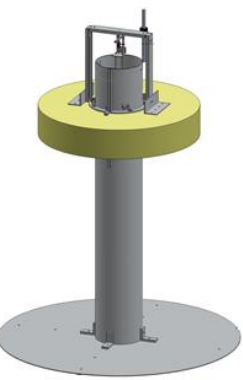

Fig7: 3D modelling of a component of wave power generator

\subsection{MATLAB \& Simulink Analysis}

Aside from the 3D model of the system, a technical drawing is generated by using SolidWorks to allow the variables of the instruments, for example, the height, length and width to be counted. This information is then fed into the Matrix Laboratory (MATLAB) to simulate the performance of the ocean wave generator. A rescale of the design was done with a ratio of 1:33, resulting in a smaller design size relative to the original measurement. To avoid any unwanted problems, an importance was given to the design to reflect the complete surface and space [13-17].

\subsection{Power take-off (PTO) Simulation and Performance}

Through MATLAB's various libraries, the component models of the wave generator were simulated to estimate the power take-off mechanism and investigate its efficiency as shown in Figure 7. In this work, hydraulic pistons were utilised as the key instruments for the PTO technique.

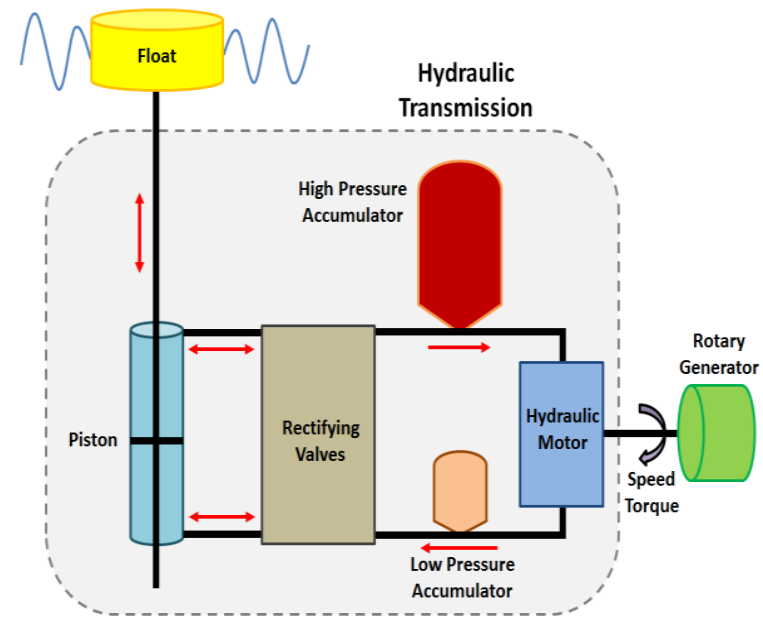

Fig 8: Block diagram of a hydraulic power take-off mechanism

The block diagram consists of the force side and response side. Applying a source code identical to the first phase, MATLAB reads and simulates the PTO mechanism once the files are placed in the same working directory. The results of the simulation are deliberated in detail in the Results and Discussion section.

The combined 3D modelling (using SolidWorks and other CAD software) allowed the developers to visualize the various components of the wave generators and transfer their parameters (dimensions, material properties, interaction among moving components) to the MATLAB and Simulink models, which in turn allowed the authors to understand its performance and efficiency of converting wave power to usable energy. As such, by modifying the design parameters of the developed 3D models, the authors were able to optimise its performance. This process continued until the best combination is found.

\section{Results and Discussion}

Using the data obtained from the simulated models, one can make conclusions related to force, power, and efficiency of power conversion. It is important to note that the type of simulated fluid used in the models and simulations implemented here were selected to be as close as possible with the real design models and implementations.

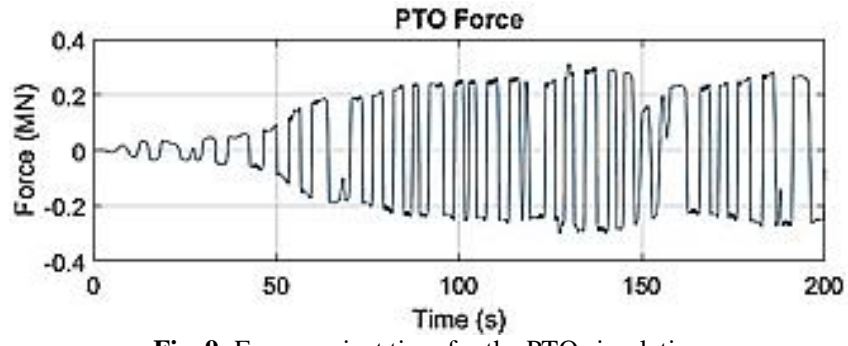

Fig. 9: Force against time for the PTO simulation

Figure 9 demonstrates the accumulative nature of wave energy. As the force grows bigger, so does the amount of electrical power generation through the process of fluid compression by the piston will run smoothly. Next point of analysis is the power loss from the generator. As power is converted from mechanical (the waves) to hydraulic (motion type conversion) to electrical (target power), there is bound to be some power losses $[8,17]$.

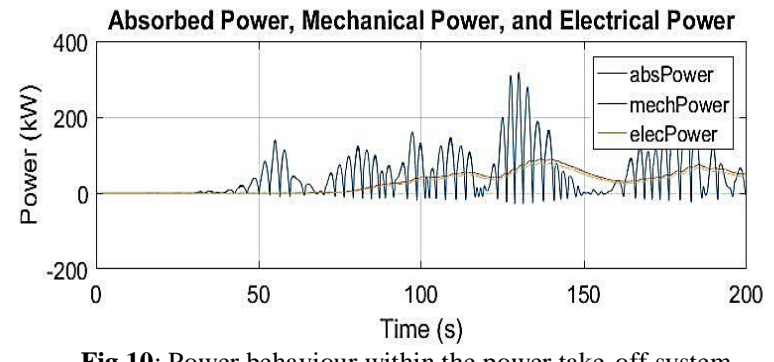

Fig 10: Power behaviour within the power take-off system

As seen in Figure 10, indeed there were some power losses during the conversion of power from mechanical to electrical. Table 1 shows the details of these observations.

Table 1: Simulated power conversion and losses

\begin{tabular}{|c|c|c|c|c|c|}
\hline Test & $\begin{array}{c}\text { Measured } \\
\text { Wave } \\
\text { Height } \\
(\mathrm{m})\end{array}$ & $\begin{array}{c}\text { Measured } \\
\text { Wave } \\
\text { Period } \\
(\mathrm{s})\end{array}$ & $\begin{array}{c}\text { Measured } \\
\text { Relative } \\
\text { Motion } \\
(\mathrm{m})\end{array}$ & $\begin{array}{c}\text { Avg. } \\
\text { Power } \\
\text { Output } \\
(\mathrm{kW})\end{array}$ & $\begin{array}{c}\text { Estimated } \\
\text { PTO } \\
\text { Damping } \\
\text { Coefficients } \\
(\mathrm{kNs} / \mathrm{m})\end{array}$ \\
\hline 1 & 2.89 & 8.01 & 1.29 & 445.61 & $3,454.43$ \\
\hline 2 & 2.91 & 7.99 & 0.66 & 278.29 & $8,173.09$ \\
\hline 3 & 2.85 & 12.06 & 2.10 & 190.65 & $1,272.97$ \\
\hline 4 & 3.04 & 13.95 & 2.10 & 118.00 & $1,051.02$ \\
\hline 5 & 2.89 & 12.03 & 2.21 & 90.31 & 541.00 \\
\hline
\end{tabular}

The energy produced from the wave generator/converter depends on the intensity of the waves (input forces). This is identified using the wave height and period. This is then coupled with the power output, as estimated by the MATLAB and Simulink models. All of which are then used to estimate the PTO damping coefficients, which are used as performance key-indicators. As discussed above, through optimization and improvement, the ideal combination of settings was found. During the tests, the power input was kept at $286 \mathrm{~kW}$ for each test. However, Table 1 shows that the maximum average power output documented was 445.61 $\mathrm{kW}$ in the first test. 


\section{Conclusion}

Ocean waves are a type of renewable energy sources that can be utilised by exploiting its motion power. Since ocean waves are a principally unexploited energy resource from which the possibility of obtaining energy is great, it is, therefore, considered as a future possible alternate resource. Simulation results in this work demonstrated the potential of wave power generators as a possible source for alternative energy. However, the effort is still needed to improve the efficiency and reduce power losses during conversion from mechanical (wave motion) to electrical energy. If and when this is achieved, this technology can have a huge impact on us as we are surrounded by oceans, allowing us to harness the clean and healthy source of power and reduce our dependency on fossil fuels.

\section{Acknowledgements}

The authors acknowledge the Innovative \& Research Management Centre (iRMC), and College of Engineering, UNITEN, for their continuous assistance of this work. The primary author wishes to acknowledge the student team for their contributions.

\section{References}

[1] Wan Nik W, Muzathik A, Samo K, \& Ibrahim M, "A Review of Ocean Wave Power Extraction: The Primary Interface", International Journal of Fluid Machinery and Systems, Vol.2, No.2, (2009), pp:156-161.

[2] Lafsah M, Ibrahim M, \& Albani A, "The Development of Wave Energy Conversion Device to Generate Electricity", $A M M$, Vol.773-774, (2015), pp:460-464.

[3] Drew B, Plummer A, \& Sahinkaya M, “A Review of Wave Energy Converter Technology", Proceedings of the Institution of Mechanical Engineers, Part A: Journal of Power and Energy, Vol.223, No.8, (2009), pp:887-902.

[4] Faizal M, Ahmed M, \& Lee Y, "A Design for Floating Point Absorber Wave Energy Converters", Advances in Mechanical Engineering, Vol.6, (2015), pp: 846097-846097.

[5] O'Sullivan DL, \& Lewis T, "Electrical Machine Options in Offshore Floating Wave Energy Converter Turbo Generators", Proceedings of the Tenth World Renewable Energy Congress (WREC X), (2008), pp:1102-1107.

[6] Henderson, R, "Design, Simulation, and Testing of A Novel Hydraulic Power Take-Off System for the Pelamis Wave Energy Converter", Renew. Energy, Vol.31, No.2, (2006), pp:271-283.

[7] Mueller, MA, "Electrical Generators for Direct Drive Wave Energy Converters", IEEE Proc. Gener. Trans. Distrib., Vol.149, No.4, (2002), pp:446-456.

[8] A. Luckins and S. P. Duttagupta, "Model predictive control strategy for direct drive PMSG and DFIG for ocean wave energy converter system," OCEANS 2016 MTS/IEEE Monterey, Monterey, CA, 2016, pp. 1-4.

[9] B Drew, A R Plummer, and M N Sahinkaya (2016) "A review of wave energy converter technologies" Proceedings of the Institution of Mechanical Engineers, Part A: Journal of Power and Energy. Vol 223, Issue 8, pp. 887 - 902.

[10] J. S. Park et. al, "Analysis of power generation for direct wave energy converter," 2017 14th International Conference on Electrical Engineering/Electronics, Computer, Telecommunications and Information Technology (ECTI-CON), Phuket, 2017, pp. 714-71

[11] C. Wang and Z. Zhang, "Key technologies of wave energy power generation system," 2017 IEEE International Conference on Mechatronics and Automation (ICMA), Takamatsu, 2017, pp. 61 65. doi: 10.1109/ICMA.2017.8015789

[12] H. M. Chen and D. R. DelBalzo, "Electromagnetic spring for Sliding Wave Energy Converter," OCEANS 2015 - MTS/IEEE Washington, Washington, DC, 2015, pp. 1-5. doi: 10.23919/OCEANS.2015.7401829

[13] F. Danang Wijaya and B. Azhari, "Analytical design and optimization of flat-quasi linear generator for sea wave power plan in South Java Ocean," 2016 8th Int. Conf. on Information
Technology and Electrical Engineering (ICITEE), Yogyakarta, 2016, pp. 1-6. doi: 10.1109/ICITEED.2016.7863276

[14] A. kumar Maurya and S. P. Singh, "A study on ocean wave power and utilization for Indian coastal region," 2017 Asian Conference on Energy, Power and Transportation Electrification (ACEPT), Singapore, 2017, pp. 1-9. doi: 10.1109/ACEPT.2017.8168544

[15] A. Wahyudie et. al, "Design of a double-sided permanent magnet linear generator for laboratory scale ocean wave energy converter," OCEANS 2017 - Anchorage, Anchorage, AK, 2017, pp. 1-5.

[16] M. R. P. Sugita, F. D. Wijaya and Sarjiya, "Design and analysis of tri core permanent magnet linear generator for wave energy conversion in south coast of Java Island," 2016 6th International Annual Engineering Seminar (InAES), Yogyakarta, 2016, pp. 256261. doi: 10.1109/INAES.2016.7821944

[17] S. Yang, H. Liu, C. Dai and Y. Li, "An application of virtual synchronous generator technology in wave energy," OCEANS 2017 - Anchorage, Anchorage, AK, 2017, pp. 1-6. 